\title{
Factors affecting dirt pick up of traffic paints in areas with different characteristics:Tehran roads as a case study
}

\begin{abstract}
This study was performed to identify the weight distribution of affecting factors in contamination of traffic paint surfaces from environmental pollutants in different municipal districts. Traffic paint samples were collected from the major roads and less busy ones of different environmental condition in Tehran and was determined using the Energy-dispersive X-ray spectroscopy (EDS). Four pollutants namely fuel consumption, brake wear, tire wear and bitumen traces are the major environmental sources can affect dirt accumulation on surfaces of traffic paints. The analysis of variance shows that obtained concentration levels of elements under study namely tungsten $(\mathrm{W})$, nickel $(\mathrm{Ni})$, chromium $(\mathrm{Cr})$, zinc $(\mathrm{Zn})$, titanium $(\mathrm{Ti})$, iron $(\mathrm{Fe})$, lead $(\mathrm{Pb})$, calcium $(\mathrm{Ca})$ and copper $(\mathrm{Cu})$ were highly significant in traffic paints collected from different areas. The quantities parameters such as "Pollution Load Index" and "Contamination Factor" were employed to identify possible levels of pollution from aforementioned pollution sources. Some elemental pairs such as $\mathrm{Fe} / \mathrm{Ti}(0.72), \mathrm{Ni} /$ $\mathrm{Cr}(0.64), \mathrm{Ca} / \mathrm{W}(0.81), \mathrm{Pb} / \mathrm{Ni}(0.70), \mathrm{Fe} / \mathrm{Cu}(0.71)$, and $\mathrm{Zn} / \mathrm{Ca}(0.81)$ have strong correlation at $5 \%$ significant level. From the obtained results, it was concluded that the main source of dirt picked up by traffic paints might be originated from combustion of fuel which is known to contain trace levels of $\mathrm{Cr}, \mathrm{Ni}$ and $\mathrm{Pb}$. The roads, in which mostly cars of diesel fuel were travelling, had higher contamination levels on the traffic paints than others. Bitumen traces and the frequency of brake use were additional factors that affected the contamination levels. The degree of contamination of traffic paints in crossroads was mostly influenced by the road dust from brake wear.
\end{abstract}

Keywords: traffic paints, dirt pick up, tire wear, bitumen, brake wear, fuel combustion
Volume 2 Issue | - 2018

\author{
Sabbagh Alvani AA, Darvishi R, Sameie H, \\ Salimi R \\ Color and Polymer Research Center, Amirkabir University of \\ Technology, Iran
}

Correspondence: Darvishi R, Color and Polymer Research Center,Amirkabir University of Technology, Tehran, Iran, Email r.darvishi@ce.iut.ac.ir

Received: December 12, 2017 | Published: January 23, 2018
Abbreviations: EDS, energy-dispersive x-ray spectroscopy; W, tungsten; Ni, nickel; $\mathrm{Cr}$, chromium; $\mathrm{Zn}$, zinc; Ti, titanium; Fe, iron; $\mathrm{Pb}$, lead; $\mathrm{Ca}$, calcium; $\mathrm{Cu}$, copper; $\mathrm{BC}$, black carbon; $\mathrm{OC}$, organic carbon

\section{Introduction}

In recent years, the dirt pick up problem and loss quality of brightness of traffic marking paints have widely attracted municipal authorities' attention. Reflective traffic paints and road marking are some of the most technologically advanced pieces of safety and traffic signs that should be there to have safe streets. ${ }^{1-5}$ The most important problem regarding with today's traffic marking paints is their low resistance to dirt pickup. The dirt pick up can occur in two ways: migration of the stains from bottom substrate to paint surface and pollutant deposition on paint surfaces. ${ }^{6}$ In the first case of the dirt type, low quality of asphalt make dirt migrate to the surface of the paint but the later happens when thousands of different solid and liquid particles suspended in the atmosphere is settled on the surface by dry or wet atmospheric deposition. The surficial dirt is made up of many components, including elemental or black carbon (BC) and organic carbon $(\mathrm{OC})$ compounds, sulfate $\left(\mathrm{SO}_{4}^{-2}\right)$, nitrate $\left(\mathrm{NO}^{3-}\right)$, trace metals, crustal material (i.e. soil particles) and sea salt. ${ }^{7}$ Dirt with amphiphilic characteristics adheres abnormally to painted surfaces (Figure 1). Pollutants emitted from different sources comes in a wide range of sizes and includes particulate matter with diameter less than or equal to $10 \mu \mathrm{m}\left(\mathrm{PM}_{10}\right)$, fine particulate matter with diameter less than or equal to $2.5 \mu \mathrm{m}\left(\mathrm{PM}_{25}\right)$, ultrafine particulate matter with diameter less than or equal to $0.1 \mu \mathrm{m}$ (PM0.1), and lastly nanoparticles pollutants with diameter less than or equal to $0.05 \mu \mathrm{m}$ (PM0.05).

Soil particles, soot, lead, asbestos, sea salt, \& sulfuric acid droplets, solid particulate matter- generally referred to as 'dust' and Liquid suspensions- commonly called 'mist' all are considered as particulate matters. These particles or traces can be transported into applied traffic paints and leave either their permanent or nonresidue stain effects. At present, the particulate or trace pollution has become primary factors affecting Tehran's urban traffic paint quality. ${ }^{3}$ Road dust and motor vehicle exhaust are two of the largest pollution sources associated with transport industry among large number of pollution sources; i.e. agricultural activities, dust storms, construction fugitive dust, Traffic resuspension, Combustion in energy and manufacturing industries (coal, coke, and heavy oil), windblown dust/construction and mining activities/industrial resuspension, etc. ${ }^{8}$ It is found that road dust which directly emitted from anthropogenic (man-made) or natural sources (i.e. primary PM) is the main source of PM10 in urban atmosphere and motor vehicle exhaust mainly affects the concentration of PM2.5 and secondary particulate matters. ${ }^{4}$ The fine particles, which are firstly deposited in the dockside and later suspended by the effects of portrelated traffic or wind, can deposit on traffic paint skins and can readily penetrate microscopic pores and increase the tendency of paints to pick up dirt subsequently. In this paper, five major categories of 
sources are considered as traffic factors which interfere in emission of pollutant and the subsequent dirt pick up in traffic paints; i.e. tire wear, brake wear, road abrasion, fuel combustion and bitumen traces. ${ }^{9}$ The contamination of traffic paints by the road dust is greatly affected by vehicle volume, speed and type, the road asphalt type, the neighboring environment and meteorological conditions, etc. This paper tries to analyze traffic paint dirt-pick up using element analysis to determine causes and the influences in different forms of urban conditions. After that it can be possible to develop quantitative parameters to serve as measure of weight distribution factors of dirt pick up control in traffic paint.

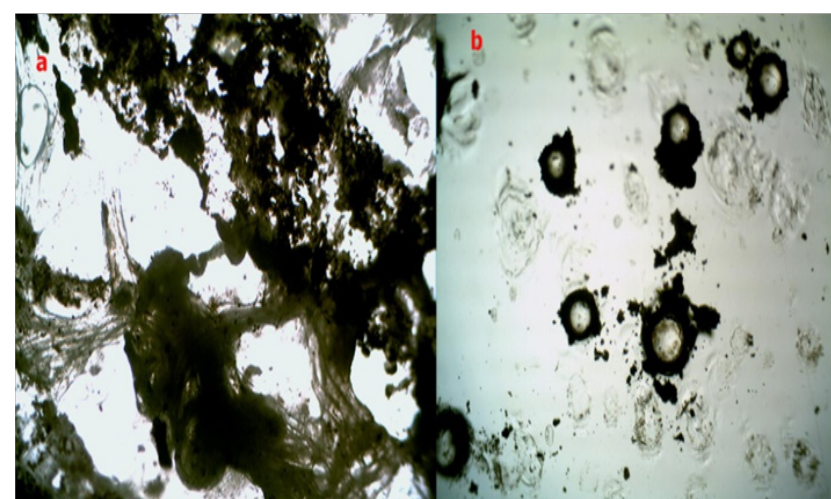

Figure I The light microscopic imaged of dirt picked up by the surface of traffic paints (taken from our laboratory) (A) $2 \mathrm{~K}$ traffic paint (b) hot melt traffic paint

\section{Experimental}

\section{Sample collection}

Total 34 samples of traffic marking paints (2-K or hot melt traffic paints) were collected from 28 urban locations in the metropolitan city of Tehran which had experienced various traffic volumes and environmental conditions (Figure 2).

The sampling sites for the traffic paints collection were categorized as follows:

$\mathrm{EF} 1=$ High volume traffic roads in which mostly cars of gasoline fuel are traveled

EF2 $=$ High volume traffic roads in which mostly cars of gasoline fuel are traveled

\section{$\mathrm{EF} 3=$ roads suspended to dust traces}

\section{$\mathrm{EF} 4=$ locations suspended to bitummen traces}

\section{EF5=locations with mostly brake wear}

The information of the number of vehicles passing through the study areas and road name was given in Table 1. The piece of traffic paints samples was collected during a dry period in late autumn following a warm and dry summer season. The piece of traffic paints adhered to some asphalt substrate is picked up using chipping hammer and were transferred to the laboratory in plastic bags for further analysis. It is being noted that two samples were obtained at each point.

\section{Road dust samples analysis}

Determination of heavy metals was done per protocol "Metal ions that are readily exchangeable between the solid and solution phases together with those that are more strongly bound within the road dust solid phases" provided by Fadigas et al. ${ }^{10}$ The road dust washed from paint surfaces and was air dried to constant weight and then sieved. Sample of $3 \mathrm{~g}$ was weighed into a mixture of $14.4 \mathrm{ml} \mathrm{HNO}_{3}$ : $\mathrm{HCl}(1: 3 \mathrm{v} / \mathrm{v})$ and 15.6 deionized water on a hot plate for $12 \mathrm{~h}$. Then the digested samples were sonicated and then heated for $1 \mathrm{~h} \mathrm{in} 70^{\circ} \mathrm{C}$ at a water bath. The digested samples were diluted to $20 \mathrm{~mL}$ and transfer into the appropriate test tube. The $\mathrm{Ca}$ in the filtrate was determined using Atomic Absorption Spectrometer. The concentration of samples is verified by Energy-dispersive X-ray spectroscopy (EDS) which can provide rapid qualitative, with adequate standards, quantitative analysis of elemental composition with a sampling depth of 1-2 microns. The light microscope was used to detect the dirt structures laid on the surface of traffic paints. The weight ratio of trace elements such as $\mathrm{C}, \mathrm{N}, \mathrm{O}, \mathrm{Ti}, \mathrm{Zn}, \mathrm{Ca}, \mathrm{W}, \mathrm{Fe}, \mathrm{Cr}, \mathrm{Ni}, \mathrm{Pb}$ and $\mathrm{Cu}$ were determined. To verify the measured content of elements, some samples are subjected to XRF analysis.

Table I Summary of information on sampling locations in Tehran and vehicle numbers and travels, 2016

\begin{tabular}{ll}
\hline Vehicle no & Road name \\
\hline EFI & Azadegan-Kazemi Highway, Fath Street \\
EF2 & Besat Highway, Chamran Highway \\
EF3 & Ashrafi and Rashid Crossroad \\
EF4 & Kaj Street, Kashan Ave \\
EF5 & Hashemi Street, Babaei Ave \\
\hline
\end{tabular}

$E F I=$ High volume traffic roads in which mostly cars of gasoline fuel are traveled

EF2=High volume traffic roads in which mostly cars of gasoline fuel are traveled

$E F 3=$ roads suspended to dust traces

EF4=locations suspended to bitummen traces

EF5=locations with mostly brake wear

\section{Criterion and characteristics}

Figure 3 illustrates the major of pollutants weight ratio, namely, particulate matters, zinc $(\mathrm{Zn})$, chromium $(\mathrm{Cr})$, lead $(\mathrm{Pb})$, copper $(\mathrm{Cu})$, nickel (Ni), emitted from four sources of tire wear, fuel combustion, road abrasion and brake wear. ${ }^{4}$ It is founded that concentration of metals in used brake pads are in the order iron $(\mathrm{Fe})>\operatorname{titanium}(\mathrm{Ti})>\mathrm{Cu}$. After the most abundant element measured in tires namely $\mathrm{Zn}$, several other metals that followed were in the order calcium $(\mathrm{Ca})>$ tungsten (W) $>$ molybdenum (Mo).

Based on the evidences given here, we can consider the most important characteristics of tire wear to be the simple summation of weight percent of Zn, Ca, W (coded by ZCW). Similarly, we can use the sum of weight percent of three elements $\mathrm{Cr}$, $\mathrm{Ni}$ and $\mathrm{Pb}$ (coded by $\mathrm{CNP}$ ) as a tracer and measure for fuel consumption and finally the summation of $\mathrm{Fe}$, Ti and $\mathrm{Cu}$ (coded by FTC) as useful criterion for pollutions originated by brake wear. As the ratio, $\mathrm{C} / \mathrm{H}$ in a bitumen reference sample is in a range of 4.5-6.3, to characterize the bitumen tracing factor in a sample we may calculate and compare the value. ${ }^{1-2}$ 


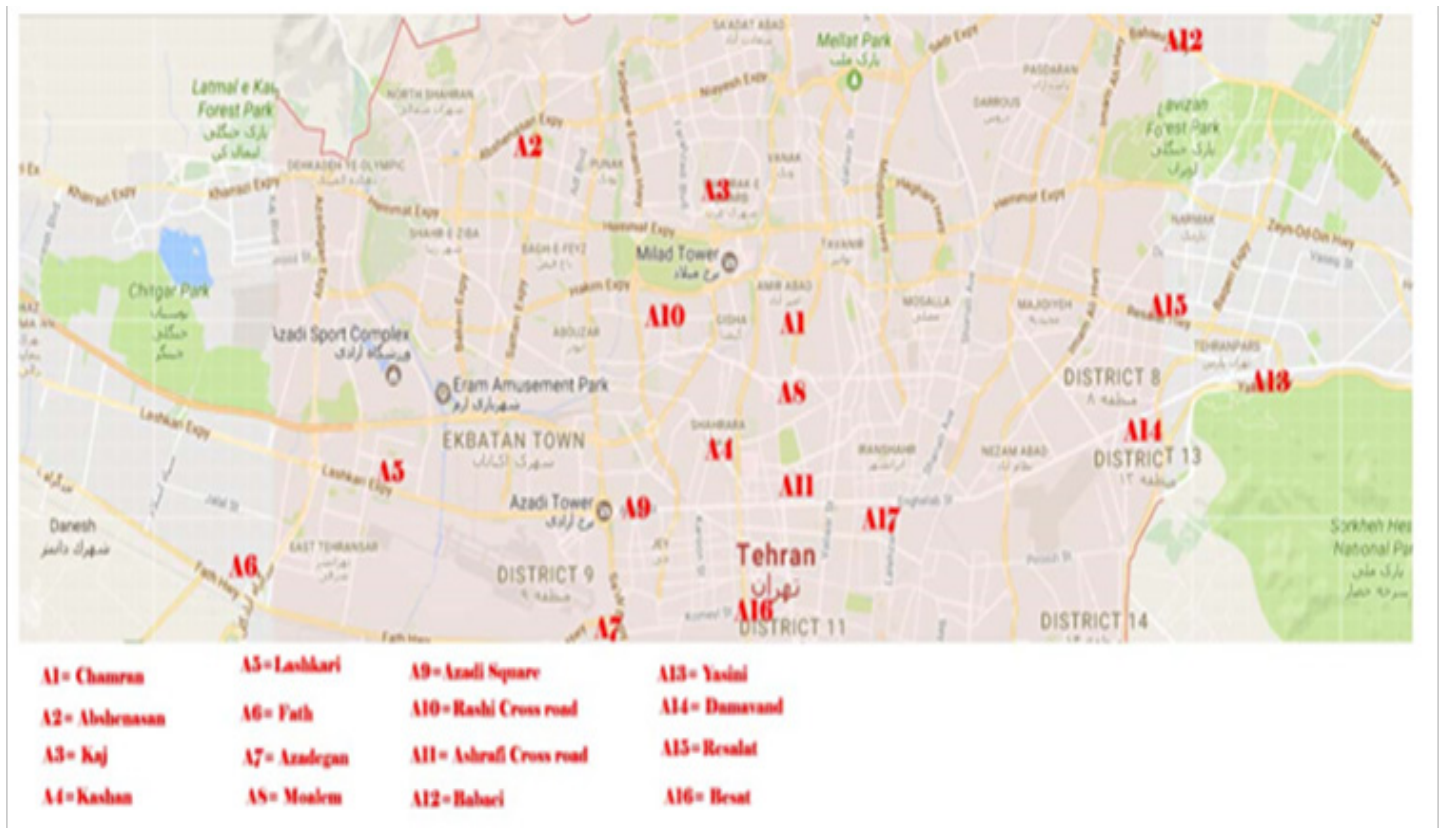

Figure 2 Map of sampling sites.

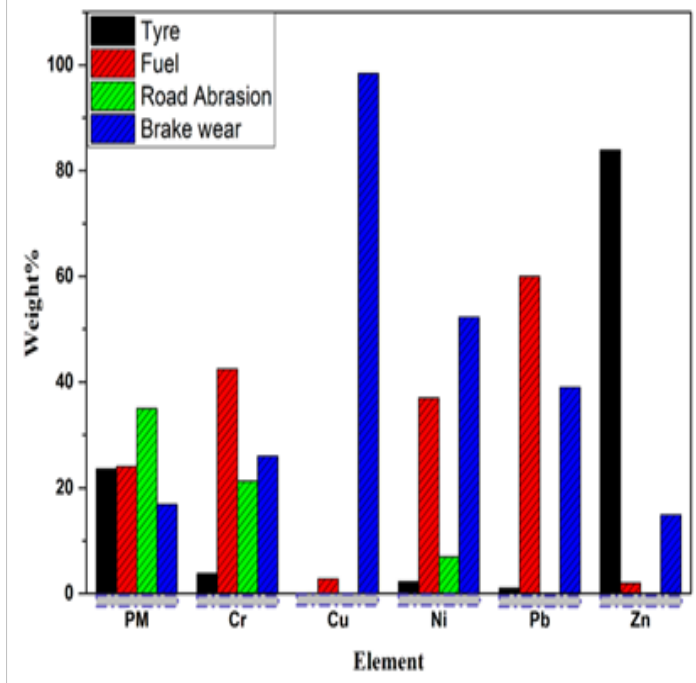

Figure 3 Characteristic elements in four main group of sources.

\section{Assessment of trace elements contamination}

Contamination factor: To assess the extent of contamination of each group of elements picked up the surface of traffic coatings, contamination factor and degree of contamination has been used. ${ }^{3}$ The $W_{f}^{i}$ is the single element index which is determined by the following equation:

$$
W_{f}^{i}=\frac{W_{0-1}^{i}}{W_{n}^{i}}
$$

Where $W_{f}^{i}$ the contamination factor of the group of elements of interest is, $W_{n}^{i}$ is the concentration of the element sample, $W_{n}^{i}$ is the background concentration. $W_{f}^{i}$ is defined per four categories: < 1 low contamination factor, 1-3 moderate contamination factors, 3-6 considerable contamination factors and $>6$ very high contamination factor.

Pollution load index: The road dust was assessed for the extent of metal pollution by employing the method based on the pollution load index (PLI) developed by ${ }^{3}$ is as follows:

$$
P L I=\sqrt[n]{C F 1 \times C F 2 \times C F 3}
$$

Where $\mathrm{n}$ is the number of main groups of elements studied and $\mathrm{CF}$ is the contamination factor calculated as described in an earlier equation. The PLI provides simple but comparative means for assessing a sample quality, where a value of PLI $<1$ denote perfection; $\mathrm{PLI}=1$ present that only baseline levels of pollutants are present and PLI $>1$ would indicate deterioration of sample quality. ${ }^{3}$

\section{Statistical analysis}

To measure how strong a relationship is between the characteristics of traffic paint dirt, the concentrations of elements content on traffic paint surfaces were subjected to Pearson's significant correlation analysis using SPSS version 19. The analysis of variance (ANOVA) was used for collected data to assess whether analyzed elements varied significantly between various locations under study, possibilities less than $0.05(p<0.05)$ will be considered statistically significant.

\section{Results and discussion}

\section{Elemental concentration of the traffic paints}

Per the study conducted, 4 main groups of characteristics mentioned above were identified in the 32 traffic paints samples collected along 18 different conditional traffic zone roads in Tehran. The weight percent for each group of element was computed and results presented in Table 2. The results revealed that, the weight percent $(\mathrm{wt} \%)$ of $\mathrm{CNP}(\mathrm{Cr}, \mathrm{Ni}, \mathrm{Pb})$ on traffic paints in azadegan-kazemi highway was the highest thus $53.4 \%$ wt where cars with gasoline fuel is more traveled. The CNP value is ranged from 17 to $60 \% \mathrm{wt}$ in all 
the samples collected. It can be observed that ZCW have the greatest contamination level of $43.35 \% \mathrm{wt}$ for Ashrafi crossroad where trace of brake line of cars was clearly observed. The value of ZCW is ranged from 8 to $44 \%$ wt. The maximum FTC concentrations (wt $\%$ ) along traffic paints sampling site belongs to Fath highway with $27.45 \%$ wt. The maximum values of bitumen trace $(48.9 \mathrm{wt} \%)$ is obtained in sampling Kaj street where the asphalt visual quality was very low.

Table 2 Elemental level in the samples collected from the different zones of Tehran

\begin{tabular}{|c|c|c|c|c|c|}
\hline Road name & CNP & ZCW & FTC & Bitumen & Others \\
\hline Chamran & 50.15 & 9.35 & 10.1 & 18.3 & 12.1 \\
\hline Abshenasan & 32.9 & 15.8 & 17.3 & 25.6 & 12.7 \\
\hline Kaj & 17.25 & 14.1 & 14.2 & 48.9 & 16 \\
\hline Kashan & 14.7 & 19 & 17.8 & 32.1 & 16.41 \\
\hline Lashkari & 53.4 & 8.3 & 10.56 & 28 & 8 \\
\hline $\begin{array}{l}\text { Lashkari } \\
\text { Yellow }\end{array}$ & 25.6 & 31.5 & 17.41 & 21.1 & 4.15 \\
\hline Fath & 20.5 & 11.65 & 27.45 & 30 & 10.4 \\
\hline Azadegan & 53.45 & 10.8 & 15.85 & 17 & 2.9 \\
\hline Molem & 21.1 & 20 & 28.5 & 20.4 & 10.6 \\
\hline Azadi Square & 48.4 & 10.7 & 19.38 & 15.9 & 5.36 \\
\hline $\begin{array}{l}\text { Rashid } \\
\text { Crossroad }\end{array}$ & 46.7 & 17.5 & 13.3 & 22.3 & 0.2 \\
\hline $\begin{array}{l}\text { Ashrafi } \\
\text { Crossroad }\end{array}$ & 32.9 & 43.35 & 3.6 & 10 & 10.7 \\
\hline Babaei & 26.6 & 21.14 & 12.3 & 20 & 20.6 \\
\hline Yasini & 47.8 & 18.9 & 8.1 & 23.1 & 2.1 \\
\hline Damavand & 36.6 & 20.35 & 19 & 14 & 10.05 \\
\hline Resalat & 20 & 9.5 & 11.5 & 25.6 & 11.1 \\
\hline Besat & 46.7 & 9.4 & 16.7 & 23.6 & 3.6 \\
\hline Hashemi & 29.5 & 11.8 & 14.1 & 20.7 & 23.9 \\
\hline
\end{tabular}

\section{Statistical analysis of heavy metals}

The analysis of variance shows that weight ratio of elements which are using in calculation of PLI and contamination factor were highly significant in traffic paint samples collected from various roads and we can rely on (Table 3 ).

\section{Correlation matrix of the elements}

The aim of this section is to present correlation matrix of the elements to verify classifying the analyzed elements into three main groups which have been discussed above thus FTC, ZCW and CNP. Some elemental pairs such as $\mathrm{Ni} / \mathrm{Cr}(0.88), \mathrm{Pb} / \mathrm{Cr}(0.75), \mathrm{Fe} / \mathrm{Ti}(0.78)$, $\mathrm{Fe} / \mathrm{Cu}(0.81), \mathrm{Zn} / \mathrm{Ca}(0.61)$ and $\mathrm{Zn} / \mathrm{W}(0.56)$, have strong correlation with each other at $1 \%$ significant levels (Table 4). The correlation analysis shows that pairs of the elements correlated strongly indicating common source of pollution.

Apeagyei et al. ${ }^{1}$ analyzed three used brake pads using XRF detecting 22 metal. They observed high concentration of Iron $(\mathrm{Fe})$, Titanium (Ti) as well as copper in samples of brake pad. The source of pairs of $\mathrm{Pb} / \mathrm{Ni}, \mathrm{Cr} / \mathrm{Ni}$ and pairs of $\mathrm{Zn} / \mathrm{W}$ and $\mathrm{Zn} / \mathrm{Ca}$ in the road dust in the is believed to come from combustion of fuel and wear-and-tear of tires, respectively.
Table 3 Summary of statistical analysis of variance of various element weight ratio (wt\%)

\begin{tabular}{llll}
\hline Element & Mean & $\begin{array}{l}\text { Standard } \\
\text { deviation }\end{array}$ & $\begin{array}{l}\text { Fischer } \\
\text { probability }\end{array}$ \\
\hline $\mathrm{W}$ & 1.67 & 0.034 & $0.023^{*}$ \\
$\mathrm{Ni}$ & 5.7 & 0.023 & $0.0 \mathrm{I}^{* *}$ \\
$\mathrm{Cr}$ & 3.5 & 0.034 & $0.01^{* *}$ \\
$\mathrm{Ti}$ & 5.1 & 0.05 & $0.03^{*}$ \\
$\mathrm{Fe}$ & 6.7 & 0.045 & $0.02^{*}$ \\
$\mathrm{~Pb}$ & 1.6 & 0.023 & $0.04 *$ \\
$\mathrm{Zn}$ & 0.05 & 0.038 & $0.00^{* *}$ \\
$\mathrm{Ca}$ & 8.7 & 0.076 & $0.04 *$ \\
$\mathrm{Cu}$ & 3.1 & 0.054 & $0.00^{* *}$ \\
\hline
\end{tabular}

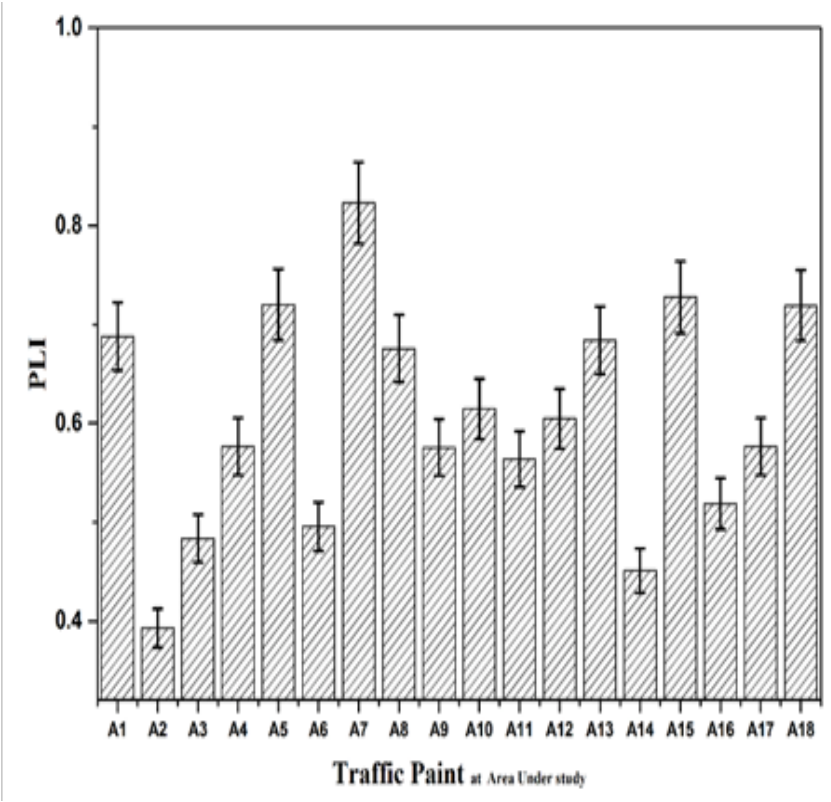

Figure 4 Estimated PLI in areas under study.

\section{Contamination factor assessment in traffic paints}

The contamination factor for each groups of element was computed and results shown in Table 2. The results show that the four main groups most have values greater than 1 in various areas signifying a range of moderate to high contamination of traffic paints from sources of fuel consumption, brake wear, tire wear and bitumen. Based on results presented in Table 5, the overall contamination factor by the eighteen areas is of the order fuel combustion $(=1.34)>$ bitumen $(=0.83)>$ tire wear $(=0.6) \approx$ brake wear. The contamination factor for the various factors except for fuel combustion was less than 1 indicating low contamination factor.

\section{Pollution load index (PLI)}

The pollution load index was calculated based on equation 2 , to effectively compare whether traffic paint in various areas and generally in Tehran suffer from a dirt picked up originated from four aforementioned sources. The PLI provides an estimate of assessing the degree of overall contamination at a traffic paint where a value of $\mathrm{PLI}<1$ denote perfection; $\mathrm{PLI}=1$ that suggest a baseline concentration 
and PLI $>1$ would show deterioration of sample quality. ${ }^{10,11}$ Based on results presented in Figure 4, fath highway has the highest PLI and abshenasan has the lowest PLI. As observed, the PLI for the various

Table 4 Correlation matrix of the analyzed elements in the traffic paints areas were less than 1 thus $\mathrm{PLI}<1$ indicating perfection (that is no overall pollution from four main groups of pollutants which have been discussed here).

\begin{tabular}{|c|c|c|c|c|c|c|c|c|c|}
\hline & $\mathbf{W}$ & $\mathbf{N i}$ & $\mathrm{Cr}$ & $\mathbf{T i}$ & $\mathrm{Fe}$ & $\mathbf{P b}$ & Zn & $\mathrm{Ca}$ & $\mathrm{Cu}$ \\
\hline W & I & -0.42 & -0.89 & 0.067 & 0.54 & -0.06 & 0.78 & 0.56 & -0.68 \\
\hline $\mathrm{Ni}$ & & 1 & 0.88 & $0.57-$ & 0.02 & 0.35 & 0.01 & -0.45 & -0.48 \\
\hline $\mathrm{Cr}$ & & & I & 0.2 & 0.7 & 0.75 & -0.11 & -0.86 & -0.55 \\
\hline $\mathrm{Ti}$ & & & & 1 & 0.78 & -0.23 & -0.47 & 0.07 & 0.63 \\
\hline $\mathrm{Fe}$ & & & & & I & 0.25 & $0.24-$ & -0.45 & 0.81 \\
\hline $\mathrm{Pb}$ & & & & & & 1 & -0.2 & -0.043 & -0.85 \\
\hline $\mathrm{Zn}$ & & & & & & & I & 0.61 & -0.23 \\
\hline $\mathrm{Ca}$ & & & & & & & & 1 & -0.02 \\
\hline $\mathrm{Cu}$ & & & & & & & & & 1 \\
\hline
\end{tabular}

Table 5 Contamination factor in the samples collected from the different zones of Tehran

\begin{tabular}{llllll}
\hline Road Name & CNP & ZCW & FTC & Bitumen & Others \\
\hline Chamran & 2.15645 & 0.40205 & 0.4343 & 0.7869 & 0.5203 \\
Abshenasan & 0.658 & 0.316 & 0.346 & 0.512 & 0.254 \\
Kaj & 0.43125 & 0.3525 & 0.355 & 1.2225 & 0.4 \\
Kashan & 0.441 & 0.57 & 0.534 & 0.963 & 0.4923 \\
Lashkari & 2.403 & 0.3735 & 0.4752 & 1.26 & 0.36 \\
Lashkari Yellow & 0.768 & 0.945 & 0.5223 & 0.633 & 0.1245 \\
Fath & 0.9225 & 0.52425 & 1.23525 & 1.35 & 0.468 \\
Azadegan & 2.6725 & 0.54 & 0.7925 & 0.85 & 0.145 \\
Molem & 0.633 & 0.6 & 0.855 & 0.612 & 0.318 \\
Azadi Square & 1.936 & 0.428 & 0.7752 & 0.636 & 0.2144 \\
Rashid Crossroad & 2.0081 & 0.7525 & 0.5719 & 0.9589 & 0 \\
Ashrafi Crossroad & 1.4147 & 1.86405 & 0.1548 & 0.43 & 0.4601 \\
Babaei & 0.931 & 0.7399 & 0.4305 & 0.7 & 0.721 \\
Yasini & 1.673 & 0.6615 & 0.2835 & 0.8085 & 0.0735 \\
Damavand & 1.464 & 0.814 & 0.76 & 0.56 & 0.402 \\
Resalat & 0.72 & 0.342 & 0.414 & 0.9216 & 0.3996 \\
Besat & 1.868 & 0.376 & 0.668 & 0.944 & 0.144 \\
Hashemi & 0.4484 & 0.5358 & 0.7866 & 0.9082 \\
\hline & & & 0.121 & 0.56 & 0.35 \\
\hline
\end{tabular}

\section{What is the reason of bitumen traces?}

The poor compounding formulation of asphalt and not paying enough attention to suitable aggregate characteristics as well as inappropriate environmental and processing conditions in the mix plant are the most important causes that make the asphalt not resist against stresses exerted by car rolling wheels. The breaking of the adhesive bond between the aggregate surface and the wetting bitumen in an asphaltic pavement or mixture is named stripping depending on many variables, including the type and use of a mix, bitumen characteristics, aggregate characteristics (such as surface texture, porosity and pore structure), environment, traffic, construction practice, and the use of anti-strip additives. Lack of attention to the optimal parameters gets one use improper bitumen and aggregates in the mix plant significantly affecting the asphalt-aggregate bond strength, and, in turn, altering the physical state of the final asphalt. This usually causes low temperature debonding at the aggregate/asphalt interface and therefore cracking of the asphalt pavement.

Under this circumstance, sealing and filling asphalt cracks with polymer modified bitumen sealants and hot applied mastics is a common road maintenance activity to prevent the intrusion of water and incompressible material into the cracks and increase its durability. Our field study and visual inspections show that there are lots of places (Figure 5) where asphalt repair mastic is applied on traffic paints and makes the surface layer of traffic paint dirty. Maybe, here is the major contributions to traffic paints dirt pick up that can deteriorate the appearance of a traffic paints, albeit further studies should be conducted to confirm the result. 


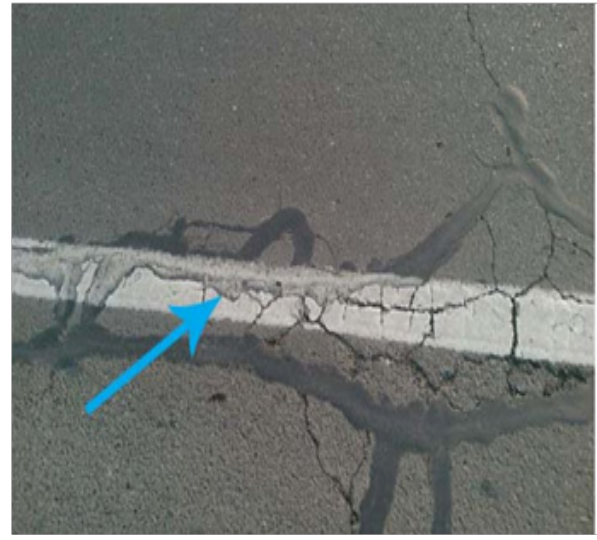

Figure 5 Cracking and sealing at asphalt surface.

\section{Conclusion}

The study was conducted to determine the weight distribution of affecting factors in contamination of traffic paint surfaces from environmental pollutants from selected major roads in municipal districts of Tehran.

Despite the overall of contamination factor of four main groups of pollutants thus FTC, ZCW and CNP were found to be lower than the alert values in most the traffic paints samples collected, the fuel combustion and bitumen have the major contribution to dirt-picked up by traffic paints. The overall degree of contamination (PLI) calculated for the four main groups of elements also confirm the previous result. The results show that the traffic paints in crossroads and roads with heavy vehicles (gasoline fuel) are more subjected to dirt picked up. Accordingly, the very poor appearance of traffic paint which is overall observed in tehra's roads can be contributed to another factor thus low quality of asphalt. The analysis of variance shows that analyzed elements weight ratio levels were highly significant in traffic paints collected from various roads. The statistical analysis of elements verifies well that some of the elements correlated strongly indicating common source of pollution. Some elemental pairs such as $\mathrm{Ni} /$ $\mathrm{Cr}(0.88), \mathrm{Pb} / \mathrm{Cr}(0.75), \mathrm{Fe} / \mathrm{Ti}(0.78), \mathrm{Fe} / \mathrm{Cu}(0.81), \mathrm{Zn} / \mathrm{Ca}(0.61)$ and $\mathrm{Zn} / \mathrm{W}(0.56)$, have strong correlation with each other at $1 \%$ significant levels.

\section{Acknowledgements}

None.

\section{Conflict of interest}

The author declares no conflict of interest.

\section{References}

1. Apeagyei Eric, Michael S Bank, John D Spengler. Distribution of heavy metals in road dust along an urban-rural gradient in Massachusetts. At mospheric Environment. 2011;45(13):2310-2323.

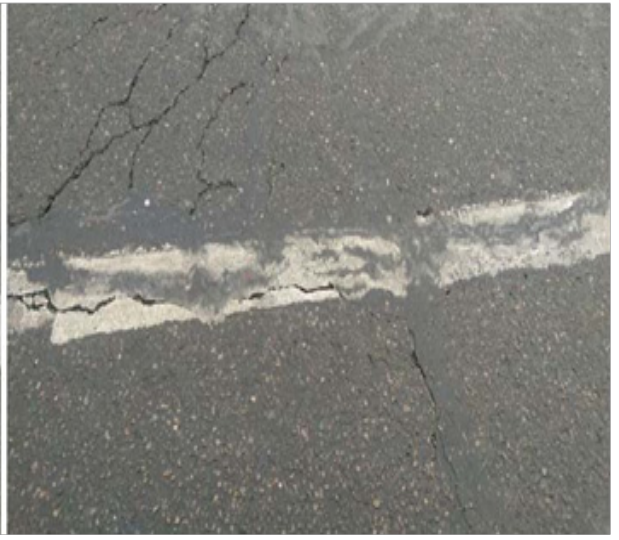

2. Yuen JQ, Olin PH, Lim HS, et al. Accumulation of potentially toxic elements in road deposited sediments in residential and light industrial neighborhoods of Singapore. J Environ Manage. 2012;101:151-163.

3. Duong TT, Byeong Kyu Lee. Determining contamination level of heavy metals in road dust from busy traffic areas with different characteristics. J Environ Manage. 2011;92(3):554-562.

4. Gunawardana C, Goonetilleke A, Egodawatta P, et al. Source characterization of road dust based on chemical and mineralogical composition. Chemosphere. 2012;87(2):163-170.

5. Liu E, Yan T, Birch G, et al. Pollution and health risk of potentially toxic metals in urban road dust in Nanjing, a mega-city of China. Sci Total Environ. 2014;476-477:522-531.

6. Wei B, Jiang F, Li X, et al. Spatial distribution and contamination assessment of heavy metals in urban road dusts from Urumqi. NW China Micro-chemical Journal. 2009;93(2):147-152.

7. Zhao H, Li X. Understanding the relationship between heavy metals in road-deposited sediments and washoff particles in urban storm water using simulated rainfall. J Hazard Mater. 2013;246-247:267-276.

8. Adachi K, Yoshiaki Tainosho. Characterization of heavy metal particles embedded in tire dust. Environment international. 2004;30(8):10091017.

9. Amato F, Pandolfi M, Moreno T, et al. Sources and variability of inhalable road dust particles in three European cities. Atmospheric Environment. 2011;45(37):6777-6787.

10. Fadigas FS, Amaral Sobrinho NMB, Anjos, LHC, et al. Background levels of some trace elements in weathered soils from the Brazilian Northern region. Sci Agric. 2010;67(1).

11. Zafra CA, Temprano J, Tejero I. Distribution of the concentration of heavy metals associated with the sediment particles accumulated on road surfaces. Environmental technology. 2011;32(9):997-1008. 